\title{
Gender and Motivations for Street Racing in Malaysia
}

\author{
Abu Sadat Nurullah \\ Department of Sociology, University of Alberta, 5-21 Tory Building, Edmonton, Alberta, \\ T6G 2H4, Canada
}

E-mail: nurullah@ualberta.ca

Pute Rahimah Makol-Abdul

Department of Sociology \& Anthropology, International Islamic University Malaysia, 53100 Kuala Lumpur, Malaysia

Saodah Abd. Rahman

Department of Comparative Religion, International Islamic University Malaysia, 53100 Kuala Lumpur, Malaysia

Accepted: June 5, 2012 Published: June 30, 2012

Doi:10.5296/jsr.v3i1.2023ＵRL: http://dx.doi.org/10.5296/jsr.v3i1.2023

\begin{abstract}
The purpose of this study was to identify social, economic, and psychological factors in street racing in Malaysia. The study also assessed gender differences in terms of the causes of participation in street racing, and the street racers' personality in terms of spiritual well-being, self-efficacy, and self-esteem. A snowball sample of 122 street racers (males, $n=99$, Mean age $=21.52, S D=4.25$; females, $n=23$, Mean age $=19.22, S D=2.47$ ) responded to self-tailored questionnaires and existing scales. For female racers, 'family violence', 'parental conflict', and 'parenting style' were the major familial factors leading to street racing. In case of male racers, 'parenting style' and 'relationship with family members' were the main causes of street racing. A sizeable percentage of male racers and female racers identified 'social contact with the street racers', 'learned attitudes which encourage street racing', 'mass media and peer influences' as causes of street racing. Both groups of respondents cited 'social pressure', 'social labeling', 'social isolation', 'opportunities for joining street racing', 'limited surveillance of authority', and 'limited recreational and sports facilities' as reasons for involvement in street racing. In terms of psychological factors, considerable percentage of male racers and female racers reported 'self-image', 'desire for recognition and attention',
\end{abstract}


'escape from social-psychological stress', and 'self-actualization' as important factors leading to street racing. Unemployment was found to be one important reason for street racing almost equally by both the groups. Significant differences in mean spiritual well-being and self-efficacy scores of male racers and female racers did not exist. However, male racers obtained significantly higher mean self-esteem score than female racers.

Keywords: street racing, psycho-social, economic, spiritual well-being, self-esteem, self-efficacy

\section{Introduction}

Illegal street racing is one of the pressing social problems which continue to cause traffic safety concerns in many societies around the world (Peak \& Glensor, 2004). Despite the inherent risk, young adults are increasingly attracted to join this growing sport and choose to break the law. Illegal street racing is defined as a form of unsanctioned and illegal auto and motorcycle racing which takes place on public roads (Wong, 2011). It is usually spontaneous, poorly-controlled, randomly organized and operates with minimal rules and safety measures (Wong, 2011). Sometimes, it is also well-planned and coordinated depending on which group of racers is organizing the event. Research indicates that young drivers from various international jurisdictions comprise between 18.8 and 69.0 percent of street racers (Vingilis \& Smart, 2009). In addition, street racing is connected to substance abuse and other risky and delinquent behaviors (Vingilis \& Smart, 2009; Wong, 2011).

In Malaysia, the police have enforced that both street racing and watching a street race is illegal (Lourdes, 2006). Illegal street races are most prevalent in many streets, roads, highways and expressways in major cities in the country. People who participate include teenagers and young adults riding either motorcycles or driving modified cars. The majority of the racers in the country are members of the 'Shell Team' which is a highly structured, well-coordinated and organized group. This team is estimated to have 6,000 members all over the country. Other racers come from loosely-organized group of teenagers who are out seeking the thrill of speed and competition. In Malay language, the Malaysian male motorcycle street racers are known as Mat Rempit and their female counterparts are known as Minah Rempit. These racers are known for their "Superman" stunts and other feats performed on their motorcycles, and they are also disreputable for their "Cilok", a kind of racing in which racers weave in-between moving and stationary traffic at high-speed (Wong, 2011).

The question that really needs an answer is why young adults join street racing and choose to violate the law. As with all high-risk behaviors, there are theoretical explanations for youth's deviant and offending behavior such as joining an illegal street racing. The choice theory, for instance, argues that delinquent behaviors are products of individual's rational decision making that the acts committed are purposeful, meaningful, beneficial, and necessary at the time they commit them (Jackson \& Knepper, 2003: 69; see also Siegel, 2002: 47). Central to 
this theory is the assumption that "humans are fundamentally rational and hedonistic; possessing free will and make deliberate decisions to behave based upon the calculation of the pain and pleasure involved" (McCaghy, Capron, \& Jameson, 2003: 12). Therefore, violation of the law is done if the rewards associated with the action are perceived to be greater than the punishment (Siegel, 2002: 48).

The trait theory, on the other hand, blames delinquent or criminal behavior on individuals' aberrant physical or psychological traits which they have very little, if any, control. This assumption implies that delinquent actions as impulsive or instinctual rather than rational choice (Siegel, 2002: 47). Some experts view that the cause of delinquency is psychological. They assume that most delinquent behaviors are manifestations of some psychological problem. The best documented and controversial of the perspectives explaining criminality are personality theory, psychoanalytic theory and criminal thinking patterns (see Arrigo, 2006: 20). These theories share the view that delinquency and crime originate in the personality structure and cognitive processes of the individual (Arrigo, 2006: 20).

The psychodynamic theory, for instance, assumed that law violations are manifestations of abnormal personality which is formed early in childhood (Siegel, 2002: 65). In contrast to the psychodynamic theory, behavioral theory claims that individual's behavior is a social product that arises in the course of interaction with others (Regoli \& Hewitt, 2006; Siegel, 2002: 67). According to leading behaviorist, B.F. Skinner, conformity and deviance are learned from the punishments and reinforcements receive by individuals in response to their behavior. In his view, children will repeat behavior which brings tangible rewards and terminate behavior which incurs punishments (Regolie \& Hewitt, 2006: 162).

Sociologically, theories on crime and deviance can be categorized into macro and micro perspectives (Jackson \& Knepper, 2003: 80). The macro perspective stresses on the importance of environment in shaping human behavior. Some of the environmental factors may include: poverty, violence, education system, and mass media, among others. This implies that law violations and offending behaviors are products of individual interactions with conditions that exist in the environment (cf. Jackson \& Knepper, 2003: 80). The micro perspective, on the other hand, gives importance to the role of agents of socialization such as the peers, parents and teachers.

Although theory and empirical evidence indicate that there are multiple factors associated with youth's deviant and offending behaviors, there is scant research that examines factors correlating with illegal street racing as one type of offending behaviors in socio-culturally unique societies such as Malaysia. In line with the above mentioned background the present study addressed the following research questions: 
1) What are the social, economic and psychological factors associated with illegal Street racing among male racers and female racers?

2) Do the social, economic and psychological causes of illegal street racing reflect gender differences?

3) Do the different gender groups differ in personality in terms of spiritual-well being, self-efficacy and self-esteem?

\section{Method}

\subsection{Sample}

A total of 122 respondents from five states of Malaysia, namely Kedah (Alor Star, Baling, Bedong, Kerian, Kuala Muda, Sungai Petani, Kulim, Kupang, Pendang, Sik, Yan and Semeling), Penang (Butterworth), Johor (Muar), Perak (Taiping and Pengkalan hulu), and Kuala Lumpur, participated voluntarily in this study. They were selected based on a snowball sampling framework due to the fact that the samples were hard to reach and the topic itself is sensitive as illegal street racing is considered a crime in Malaysia. The largest samples were drawn from Kedah state $(91.8 \%)$. All of them were Malay and Muslim by religion. The majority $(81.1 \%)$ of them were male racers $(n=99$, Mean age $=21.52, S D=4.25)$, and $18.9 \%$ were female racers $(n=23$, Mean age $=19.22, S D=2.47)$. The reason behind the disproportion of gender may be that street racing is largely dominated by males, and females were unwilling turn up during the data collection period for social pressure.

In terms of level of education, $71.3 \%$ obtained secondary school certificate, $8.2 \%$ completed primary school certificate, and 6.6\% completed diploma. Very few obtained a university degree $(3.3 \%)$. None of them were uneducated. Most of the respondents were laborers (36.9\%), followed by students (30.3\%), unemployed $(9.8 \%)$, and $9.0 \%$ were involved in business. Interestingly, 4.1 percent of them indicated their employment status as 'racing'. Most of them were from extended family (49.3\%), followed by nuclear family (43.3\%), and very few were from single parent family (7.5). The mean family size was $6.53(S D=2.58)$. Most of their fathers were laborers (30.3\%), followed by rubber tapper $(10.7 \%)$, business $(8.2 \%)$, and $23.0 \%$ were involved in other types of occupations. Interestingly, few fathers (3.3\%) were in the police department. And $22.1 \%$ did not mention their father's occupation. Similar to the respondents, most of their fathers (29.5\%) obtained secondary education, followed by primary education (12.3\%), university (7.4\%), and diploma (2.5\%). However, a large number of respondents $(48.4 \%)$ did not mention their father's highest educational attainment. Most of their mothers were housewives (64.8\%), and few were rubber tapper (2.5\%) and other types of occupations (17.2\%). The educational achievement of their mothers showed quite similar pattern to their fathers. 


\subsection{Measures}

The participants responded to a 3-point Likert type questionnaire as agree (3), unsure (2), or disagree (1). The seven-page survey instrument was a modified Malay version of the combined self-tailored questionnaire and existing scales. The self-tailored questionnaire was categorized into 5 key factors: familial, socialization, societal, psychological and economic factors, and consisted of 33 items, each item representing a topic relevant to the cause leading to street racing. It assessed the attitude of male racers and female racers towards the reason for joining street racing. In addition, the existing scales were employed to evaluate the personality of male racers and female racers in terms of spiritual well-being, self-efficacy, and self-esteem. The questionnaire also asked for demographic characteristics such as age, gender, marital status, level of education and occupation of the respondents, their parents' level of education and occupation, family size, family structure, and place of residence. The existing standardized scales were used to measure spiritual well-being, self-efficacy, and self-esteem of the respondents.

\subsection{Procedures}

The survey was conducted in April 2007 in the state of Kedah, Malaysia. One hundred and twenty two street racers were interviewed and surveyed. Participation in the study was voluntary. These street racers were asked by the researchers to gather in certain places in Kedah, Malaysia. In many cases, the street racers gathered in certain secret places at certain times according to their conveniences, and informed the researchers their location by SMS text message to get away from police. The process of data collection was secret because they had fear of harassment by the police. A large number of street racers were drawn from their annual mass-gathering ceremony in Kedah. Since the street racers were fearful of police arrest, many of them were reluctant to participate in the study initially. They were also suspicious of the actual identity of the researchers. However, this problem was solved after a briefing session was organized by the three local leaders who helped facilitate the data collection. In this session, the researchers were introduced by three local leaders and the objectives of the study were explained. The questionnaire was group administered during five sessions. During these sessions, data from all 122 respondents were gathered through survey questionnaire.

\section{Results}

We used SPSS 17.0 for window for quantitative data analysis, which included computation of percentages, mean scores, standard deviations, $t$-test, and inter-scale correlations. 


\subsection{Reasons for Involvement in Street Racing}

Results summarized in Table 1 indicate social, economic, and psychological factors leading to street racing by youth. For the sake of convenience the social factors have been classified further into three categories: familial factors, socialization factors, and societal factors. Among familial factors 'parents' conflict' had the highest approval (34.8\%) among female racers, followed by 'unstable or conflictive family' (30.4\%), 'parenting style' (26.1\%), and 'family violence' (26.1\%). In case of male racers 'relationship with family members' was the main cause of street racing (31.3\%), followed by 'parenting style' (29.3\%). However, 'parent-school pressure' and 'lack of parental guidance' had little significance behind involvement in street racing for both male racers and female racers. For most of the familial factors the percentages of disagreements were higher between both the groups; yet the percentages of agreement seemed to be alarming.

In terms of socialization factors, 'peer influence' was the major factor in street racing $(65.2 \%$ for female racers, and $55.6 \%$ for male racers). A sizeable percentage of male racers and female racers identified 'social contact with the street racers' $(34.8 \%$ for female racers, and $44.4 \%$ for male racers), and 'learned attitudes that encourage street racing' (43.5\% for female racers, and $40.4 \%$ for male racers) as the key factors for involvement in street racing. However, 'mass media influence' displayed gender difference $(21.7 \%$ for female racers, and $49.5 \%$ for male racers).

Similarly in societal factors, 'limited recreational facilities for youth' (63.6\%) and 'limited sports facilities' (59.6\%) had the highest approval among male racers, followed by 'opportunities for joining street racing' (54.5\%), 'lack of opportunities for legitimate advancement' (49.5\%), 'limited surveillance of authority' (42.4\%), 'protest against social inequalities' (40.4\%), 'social labeling' (37.4\%), and 'social pressure' (34.3\%). In case of female racers, 'limited surveillance of authority' (52.2\%) was the main cause for involvement in street racing, followed by 'limited recreational facilities for youth' (39.1\%) and 'opportunities for joining street racing' (34.8\%). Other societal factors for female racers were 'poor community integration', 'social pressure', 'social isolation from family and friends', and 'limited sports facilities' (30.4\% each). 
Table 1. Reasons for Involvement in Street Racing (male, $n=99$; female, $n=23$ ):

\begin{tabular}{|c|c|c|c|c|c|c|}
\hline \multirow[t]{2}{*}{ Factors } & \multicolumn{2}{|c|}{$\%$ Agree } & \multicolumn{2}{|c|}{$\%$ Unsure } & \multicolumn{2}{|c|}{$\%$ Disagree } \\
\hline & Male & Female & Male & Female & Male & Female \\
\hline \multicolumn{7}{|l|}{ Familial factors: } \\
\hline 1. Parent-school pressure & 11.1 & 13.0 & 30.3 & 47.8 & 58.6 & 39.1 \\
\hline 2. Family violence & 7.1 & 26.1 & 25.2 & 13.0 & 67.7 & 60.9 \\
\hline 3. Parents' conflict & 13.1 & 34.8 & 20.2 & 8.7 & 66.7 & 56.5 \\
\hline 4. Lack of parental guidance & 12.1 & 13.0 & 25.2 & 26.1 & 62.6 & 60.9 \\
\hline 5. Parenting style & 29.3 & 26.1 & 28.3 & 34.7 & 42.4 & 39.1 \\
\hline 6. Relationship with family members & 31.3 & 21.7 & 28.3 & 30.4 & 40.4 & 47.8 \\
\hline 7. Unstable or conflictive family & 19.2 & 30.4 & 28.3 & 13.0 & 52.5 & 56.5 \\
\hline \multicolumn{7}{|l|}{ Socialization Factors: } \\
\hline 1. Social contact with street racers & 44.4 & 34.8 & 31.3 & 21.7 & 24.2 & 43.5 \\
\hline 2. Learned attitudes that encourage street racing & 40.4 & 43.5 & 32.3 & 13.0 & 27.3 & 43.5 \\
\hline 3. Learned mass media influence & 49.5 & 21.7 & 29.3 & 43.5 & 21.2 & 34.8 \\
\hline 4. Peer influence & 55.6 & 65.2 & 25.3 & 4.3 & 19.2 & 30.4 \\
\hline \multicolumn{7}{|l|}{ Societal Factors: } \\
\hline 1. Poor community integration & 24.2 & 30.4 & 38.3 & 39.1 & 37.4 & 30.4 \\
\hline \multicolumn{7}{|l|}{ 2. Lack of opportunities for legitimate } \\
\hline advancement & 49.5 & 13.0 & 32.3 & 21.7 & 18.2 & 65.2 \\
\hline 3. Protest against social inequalities & 40.4 & 13.0 & 41.4 & 39.1 & 18.2 & 47.8 \\
\hline 4. Social pressure & 34.3 & 30.4 & 33.3 & 34.8 & 32.3 & 34.8 \\
\hline 5. Social labeling & 37.4 & 21.7 & 35.3 & 43.5 & 27.3 & 34.8 \\
\hline 6. Social isolation from family and friends & 29.3 & 30.4 & 38.4 & 26.1 & 32.3 & 43.5 \\
\hline 7. Opportunities for joining street racing & 54.5 & 34.8 & 27.3 & 21.7 & 18.2 & 43.5 \\
\hline 8. Limited surveillance of authority & 42.4 & 52.2 & 30.3 & 39.1 & 27.3 & 8.7 \\
\hline 9. Limited recreational facilities for youth & 63.6 & 39.1 & 12.1 & 30.4 & 24.2 & 30.4 \\
\hline 10. Limited sports facilities & 59.6 & 30.4 & 26.2 & 56.5 & 14.1 & 13.0 \\
\hline 11. Weak links to conventional society & 23.2 & 13.0 & 45.4 & 30.4 & 31.3 & 56.5 \\
\hline \multicolumn{7}{|l|}{ Psychological factors: } \\
\hline 1. Social alienation & 22.2 & 8.7 & 42.4 & 52.2 & 35.4 & 39.1 \\
\hline 2. Self-image & 45.5 & 39.1 & 38.3 & 47.8 & 16.2 & 13.0 \\
\hline 3. Desire for recognition and attention & 52.5 & 60.9 & 36.3 & 21.7 & 11.1 & 17.4 \\
\hline 4. Escape from social-psychological stress & 52.5 & 56.5 & 32.3 & 34.8 & 15.2 & 8.7 \\
\hline 5. Self-actualization & 66.7 & 60.9 & 23.2 & 26.1 & 10.1 & 13.0 \\
\hline
\end{tabular}




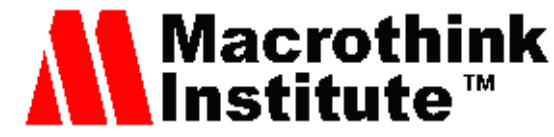

Economic factors:

1. Unemployment

2. Low salary

3. Limited economic opportunities

4. Inflation

5. Economic background of the parents
36.4

39.1

24.2

$\begin{array}{lll}25.3 & 30.4 & 45.4\end{array}$

$45.5 \quad 17.4 \quad 38.4$

47.5

26.1

31.3

$\begin{array}{lll}33.3 & 21.7 \quad 34.3\end{array}$ $\begin{array}{ll}21.7 & 39.4\end{array}$

39.1

$39.1 \quad 29.3$

$\begin{array}{ll}47.8 & 16.2\end{array}$

$30.4 \quad 21.2$

30.4

34.8

43.5

In terms of psychological factors, 'self-actualization' was the major factor in street racing (60.9\% for female racers, and $66.7 \%$ for male racers). Considerable percentage of male racers and female racers reported 'desire for recognition and attention' (60.9\% for female racers, and $52.5 \%$ for male racers), 'escape from social-psychological stress' (56.5\% for female racers, and $52.5 \%$ for male racers), and 'self-image' (39.1\% for female racers, and $45.5 \%$ for male racers) as important factors leading to street racing.

Unemployment was found to be one important reason for street racing almost equally by both the groups (39.1\% for female racers, and $36.4 \%$ for male racers). In case of male racers, 'inflation' (47.5\%), 'limited economic opportunities' (45.5\%), and 'economic background of the parents' $(33.3 \%)$ were the chief factors behind it. In the latter cases, female racers differed from male racers, because 'limited economic opportunities' (17.4\%), 'economic background of the parents' $(21.7 \%)$, and 'inflation' $(26.1 \%)$ were not the significant contributing factors.

\subsection{Effect of gender on youth involvement in street racing}

Overall, both the social (particularly societal and socialization) and psychological factors had the highest approval for the male racers and female racers as the main reasons for youth involvement in street racing. In case of female racers, 'peer influence', 'self-actualization', and 'desire for recognition and attention'; and in case of male racers, 'limited recreational facilities for youth' and 'self-actualization' were the chief factors for that (above $60 \%$ in each case).

Table 2, 3, and 4 show the influence of personality of male and female racers in terms of self-esteem, self-efficacy, and spiritual well-being on street racing in Malaysia. An independent-sample t-test was conducted to evaluate the hypothesis that the male racers and female racers differ in terms of their mean spiritual well-being, self-efficacy, and self-esteem scores. Significant differences in mean spiritual well-being and self-efficacy scores of male racers and female racers did not exist. However, the test was significant in terms of their self-esteem scores, $t(120)=2.25, p=.03$. Male racers obtained significantly higher mean self-esteem score $(M=18.41, S D=2.33)$ than female racers $(M=17.19, S D=1.75)$. 
Table 2. Mean Spiritual Well-being Scores and Standard Deviations by Gender

\begin{tabular}{|lrrrrr|}
\hline Gender & $n$ & Mean & $S D$ & $t$ & $p$ \\
\hline Male & 87 & 36.71 & 4.89 & & \\
& & & & 0.77 & 0.44 \\
Female & 19 & 37.63 & 3.74 & & \\
\hline
\end{tabular}

Table 3. Mean Self-efficacy Scores and Standard Deviations by Gender

\begin{tabular}{|lrrrrr|}
\hline Gender & $n$ & Mean & $S D$ & $t$ & $p$ \\
\hline Male & 81 & 20.09 & 2.82 & & \\
& & & & 1.2 & 0.23 \\
Female & 21 & 19.24 & 3.19 & & \\
\hline
\end{tabular}

Table 4. Mean Self-esteem Scores and Standard Deviations by Gender

\begin{tabular}{|lrrrrr|}
\hline Gender & $n$ & Mean & $S D$ & $t$ & $p$ \\
\hline Male & 85 & 18.41 & 2.33 & & \\
& & & & 2.25 & 0.03 \\
Female & 21 & 17.19 & 1.75 & & \\
\hline
\end{tabular}

Result summarized in Table 5 displays inter-scale correlations among spiritual well-being, self-efficacy, and self-esteem. Spiritual well-being scores of respondents correlated positively with their self-efficacy scores $(.32, p<.004)$. Self-efficacy scores $(.53, p<.02)$ correlated positively with self-esteem scores of male racers $(.24, p<.03)$, but significant correlation between these two variables did not emerge in case of female racers. 
Table 5. Mean Self-esteem Scores and Standard Deviations by Gender

\begin{tabular}{|lccc|}
\hline Inter-scale Correlations & \multicolumn{3}{l|}{} \\
\hline & 1 & 2 & 3 \\
1. Spiritual Well-being & Spiritual Well-being & Self-efficacy & Self-esteem \\
2. Self-efficacy & - & $0.32^{* *}$ & 0.07 \\
3. Self-esteem & $0.53^{*}$ & - & $0.24^{*}$ \\
\hline
\end{tabular}

**. Correlation is significant at the 0.01 level (2-tailed).

*. Correlation is significant at the 0.05 level (2-tailed).

Upper diagonal represents male respondents $(n=78-87)$.

Lower diagonal represents female respondents $(n=19-21)$.

\section{Discussion}

The focus of this research was to explore the social, psychological, and economic factors leading to street racing. It also assessed the gender differences among the male racers and female racers in terms of the causes of their participation in illegal street racing. The differences in their personality in terms of spiritual-well-being, self-efficacy and self-esteem were also examined.

The data analyses indicate that social and psychological factors significantly contribute to street racing in Malaysia. Among the social factors, 'peer influence', 'limited recreational facilities for youth', 'social contact with street racers', 'learned mass media influence', 'lack of opportunities for legitimate advancement', 'opportunities for joining street racing', 'limited surveillance of authority', and 'limited sports facilities' were the key factors for youth involvement in street racing for both male racers and female racers.

Psychologically, the reported chief causes of street racing were 'self-actualization', 'desire for recognition and attention', 'escape from social-psychological stress', and 'self-image'. Economic factors have also influenced the male racers and female racers to join street racing, albeit in a less noteworthy figure. The economic factors were less obvious as compared to other factors. This may be because of economic sufficiency among the male racers and female racers, since they can afford to purchase the vehicles for racing on their own. The principal economic variables reported were 'inflation', 'limited economic opportunities', and 'economic background of the parents'. Unemployment was also identified as one important reason for street racing almost equally by both the female racers, and male racers. 
It can be inferred from the study that the phenomenon of street racing is widespread in Malaysian society due to lack of social stability as well as limited recreational facilities for youth in pursuing their aspirations in a legitimate way. The breakdown of family system, high divorce rate (Kausar, 2005: 19-21), and the tendency of violation of social norms may be influential factors for youth involvement in street racing. The primary socialization factors such as peer groups and mass media might have strongly influenced the act of street racing. In addition, the psychological desire for self-fulfillment, and self-gratitude and attention might also have contributed to this behavior considerably. It can be noted that in this post-modern era, individuals suffer from lack of psychological satisfaction in their life. Therefore, they may crave for realizing their emotional fulfillment in whatever means they can, including enjoying a race on the street which may cause harm to them as well as to others. It can be deduced from this study that illegal street racing provides the male racers and female racers an avenue to satisfy many of their psychological and emotional needs.

We found gender differences in several factors causing street racing. In case of female racers, 'peer influence', 'self-actualization', 'limited surveillance of authority', 'escape from social-psychological stress', and 'desire for recognition and attention'; and in case of male racers, 'limited recreational facilities for youth' and 'self-actualization' were reported to be the major factors leading to street racing. For female racers, 'family violence', 'parental conflict', and 'conflictive family' were the major familial factors leading to street racing. In case of male racers, 'parenting style' and 'relationship with family members' were the main causes of street racing. The personality of male racers and female racers differed in terms of their mean spiritual well-being, self-efficacy, and self-esteem scores. Although significant differences in mean spiritual well-being and self-efficacy scores of male racers and female racers did not exist, male racers obtained significantly higher mean self-esteem score than female racers. Spiritual well-being scores of both the group correlated positively with their self-efficacy scores. Self-efficacy scores correlated positively with self-esteem scores of male racers, but significant correlation between these two variables did not emerge in case of female racers.

The present study implies the prevalence of female involvement in street racing in Malaysia, particularly among Muslim females. While conducting the research, they were found to smoke openly, not covering their aurah, and mixing freely with their boyfriends. It reflects the influence of social change and modernization on behaviors of Malay females in a country like Malaysia where Muslims are the majority. This poses a challenge to Islamic identity of Malay females who are involved in street racing. The phenomenon of street racing is, no doubt, a serious problem of our society. All concerned quarters have to think seriously about this behavior and support more extensive empirical research on this issue so that feasible methods for controlling street racing can be developed and thus prevention of negative outcomes of this menace could be possible. 


\subsection{Limitations and suggestions for further research}

The data of this study came from a cross-sectional survey of a sample of street racers from five states of Malaysia. Another limitation is that a representative sample was not feasible due to limited time and resources, and the sensitivity of the research topic (i.e., street racing being illegal in Malaysia). One cannot conclude that the results obtained are representative of all the street racers in Malaysia and thus generalization of the present findings is limited. This study is also limited by its use of self-report questionnaire. Future research should use more heterogeneous and larger representative random samples of street racers from all over Malaysia. In addition, the use of ethnographic fieldwork and longitudinal participant observation in data collection may be useful for obtaining a holistic picture of the phenomenon.

\section{Acknowledgements}

An earlier version of this paper was presented at the International Conference on the Status of Muslim Women in Contemporary Societies: Realities and Prospects. Kuala Lumpur: International Institute for Muslim Unity, IIUM, 14-16 August, 2007. We thank Dr. Syed Sohail Imam for his assistance with data analysis.

\section{References}

Arrigo, B. A. (2006). Criminal behavior: A system approach. Upper Saddle River, NJ: Pearson Education.

Jackson, M. S., \& Knepper, P. (2003). Delinquency and justice. Boston, MA: Pearson Education.

Kausar, Z. (2005). Social ills in Malaysia: Causes and remedies. Kuala Lumpur: Research Centre, International Islamic University Malaysia.

Lourdes, M. (2006). Illegal racers and spectators to face heavier fines and longer jail terms. The Star Online, September 15. Retrieved May 15, 2012, from http://thestar.com.my/news/story.asp?file=/2006/9/15/nation/15442964\&sec=nation

McCaghy, C. H., Capron, T. A., \& Jamieson, J. D. (2003). Deviant behavior: Crime, conflict, and interest groups. Boston, MA: Pearson education.

Mooney, L. A., Knox, D., \& Schacht, S. (2002). Understanding social problems (3 ${ }^{\text {rd }}$ ed.). Australia: Wadsworth.

Peak, K. J., \& Glensor, R. W. (2004). Street racing. Washington, DC: US Department of Justice, Office of Community Oriented Policing services. 
Regoli, R. M., \& Hewitt, J. D. (2006). Delinquency in society $\left(6^{\text {th }}\right.$ ed.). New York: McGraw-Hill.

Siegel, L. J. (2002). Juvenile delinquency: The core. Australia: Wadsworth.

Vingilis, E., \& Smart, R. G. (2009): Street racing: A neglected research area? Traffic Injury Prevention, 10(2), 148-156.

Wong, L. P. (2011). Socio-demographic and behavioural characteristics of illegal motorcycle street racers in Malaysia. BMC Public Health, 11, 446. doi:10.1186/1471-2458-11-446 